\title{
Dielectric properties and resistance to fatigue failure of different barrier layers prepared on flexible stainless-steel foils by ion-beam assisted deposition
}

\author{
Yu-qiong Li ${ }^{\text {a,b }}$, Zhi-nong Yu ${ }^{\text {b,* }}$, Jian Leng ${ }^{\mathrm{c}}$, Hua-qing Wang ${ }^{\mathrm{d}}$, She Chen ${ }^{\mathrm{a}}$, Yu-hui Dong a , Gang Jin ${ }^{\mathrm{a}, * *}$ \\ a National Microgravity Laboratory (NML), Institute of Mechanics, Chinese Academy of Sciences, Beijing 100190, PR China \\ b School of Optoelectronics, Beijing Institute of Technology, Beijing 100081, PR China \\ c Tianjin Key Laboratory of Optical Thin Films, Tianjin Jinhang Institute of Technical Physics, Tianjin 300192, PR China \\ d Optical Thin Film Center, Daheng New Epoch Technology Inc., Beijing 100070, PR China
}

\section{A R T I C L E I N F O}

\section{Article history:}

Received 19 August 2011

Received in revised form 28 May 2012

Accepted 24 June 2012

Available online 28 June 2012

\section{Keywords:}

Barrier layer

Composite barrier

Dielectric properties

Fatigue testing

Stainless-steel foil

Ion beam assisted deposition

Metal oxides

\begin{abstract}
A B S T R A C T
A stainless-steel foil is an attractive candidate for the substrate of flexible display devices and integrated solar modules. For electrical insulation and ion diffusion reduction, a barrier layer should be coated on the stainless-steel foil surface. In this study, different barrier layers such as $\mathrm{SiO}_{x}, \mathrm{TaO}_{x}, \mathrm{TiO}_{x}$ and $\mathrm{TaO}_{x} / \mathrm{SiO}$ x were prepared on the flexible stainless-steel foils (SUS 304) by ion-beam assisted deposition. The dielectric properties of the barrier layers, including resistance, reactance, leakage current density, breakdown field strength and performance index, were investigated. The resistance to fatigue failure of the barrier layers was evaluated by insulating tests after the specimen foils were flattened. The results show that the dielectric properties and the resistance to fatigue failure of the $\mathrm{TaO}_{x} / \mathrm{SiO}_{x}$ composite barrier layer are better than those of the $\mathrm{SiO}_{x}$ or the $\mathrm{TaO}_{x}$ barrier layer. The best dielectric properties and resistance to fatigue failure are achieved with the 4- $\mu \mathrm{m}$ thick $\mathrm{TaO}_{x} / \mathrm{SiO}_{x} \mathrm{com}_{-}$ posite barrier layer.
\end{abstract}

(c) 2012 Elsevier B.V. All rights reserved.

\section{Introduction}

Most commercial thin-film solar modules and display devices are fabricated on rigid glass substrates, but plastic film substrates and metal foil substrates are attracting attention because of their flexibility. While the concern about the chemical stability, the heat resistance and the moisture resistance limits the use of the plastic film substrates, the suitability of the stainless-steel foil substrates has been studied and some prototype display devices have been produced [1-3]. Besides, due to the impact resistance and low price compared to plastic films $[4,5]$, stainless-steel foil substrates are widely used in the solar energy field.

For the electrical conduction, a barrier layer should be coated on the surface of the stainless-steel foil substrate. Not only does the barrier layer provide electrical insulation between the metal substrate and the monolithically interconnected cell, but also reduce the impurity diffusion from the metal substrate into the above functional layers. Shi et al. reported that the $\mathrm{ZnO}_{x}$ diffusion barrier layers prepared by direct current magnetron sputtering could strongly reduce the diffusion of Fe ions from the stainless-steel substrates into the $\mathrm{Cu}\left(\operatorname{In}_{x} \mathrm{Ga}_{1-x}\right) \mathrm{Se}_{2}$ thin films [6]. Evans et al. investigated $\mathrm{SiO}_{x}$ barrier layers deposited on

\footnotetext{
* Corresponding author. Tel.: + 861068913259 11; fax: +86 1068915225

** Corresponding author. Tel./fax: + 861082544138 .

E-mail addresses: znyu@bit.edu.cn (Z.Yu), gajin@imech.ac.cn (G. Jin).
}

stainless-steel substrates using flame-assisted chemical vapor deposition, and found that the $\mathrm{SiO}_{x}$ layers significantly reduced ion diffusion into the $\mathrm{TiO}_{x}$ thin films and improved the photo-catalytic activity of the $\mathrm{TiO}_{x}$ samples [7]. Jin et al. adapted tantalum nitride films prepared by radio frequency magnetron sputtering as barriers against the diffusion of copper into the electronic device substrates [8]. Herz et al. reported that a suitable $\mathrm{SiO}_{x}$ dielectric barrier layer could be obtained by plasma-enhanced chemical vapor deposition (PECVD) on a titanium metal foil substrate $[9,10]$. In a previous work, we investigated the electrical insulation and bending properties of $\mathrm{SiO}_{x}$ barriers prepared by different methods such as ion-beam assisted deposition (IBAD), sol-gel deposition and PECVD, and the results showed that the best electrical insulation and bending properties of the barrier layers were achieved with $4-\mu \mathrm{m}$ thick $\mathrm{SiO}_{x}$ barrier layers prepared by PECVD [11]. However, there have been few reports on the comparison of dielectric properties and resistance to fatigue failure among $\mathrm{SiO}_{x}, \mathrm{TaO}_{x}, \mathrm{TiO}_{x}$ and $\mathrm{TaO}_{x} / \mathrm{SiO}_{x}$ barrier layers prepared by IBAD. In this paper, $\mathrm{SiO}_{x}, \mathrm{TaO}_{x}, \mathrm{TiO}_{x}$ and $\mathrm{TaO}_{x} / \mathrm{SiO}_{x}$ barrier layers were prepared by IBAD method on stainless-steel foil substrates, and their dielectric properties and resistance to fatigue failure were studied and compared.

\section{Experimental details}

The flexible stainless-steel foils (SUS 304, $150 \mu \mathrm{m}$ ) without deep scratches and rolling traces were used as substrates in the experiment, 
the surfaces of which were pre-treated by mechanical polishing and electrolytic polishing as our previous work [11]. After the polishing, the surface medium roughness $\left(R_{\mathrm{a}}\right)$ was $1.7 \mathrm{~nm}$ and maximum roughness $\left(R_{\mathrm{t}}\right) 19.38 \mathrm{~nm}[12,13]$.

An electron beam evaporation system (ZZSX-800ZA, Beijing Beiyi Innovation Vacuum Technology Co., Ltd) has been used in the experiment. The main characteristics of the system are as follows: (1) the vacuum pump is a low-temperature condensate pump, fabricated by Ulvac corporation of Japan, and the ultimate vacuum is about $5 \times 10^{-5} \mathrm{~Pa}$; (2) the model of electron gun is THG-6, which is manufactured by the East Gade Ltd. of China; (3) the thickness monitor system is a MDC-360 quartz crystal control device, the thickness resolution of which is $0.01 \mathrm{~nm}$; (4) the ion source adopted is Kauffman type, which is produced by Space Research Center of Beijing.

The substrates were cleaned with commercial detergent and de-ionized water before being loaded into the e-beam system. Prior to deposition, the substrates were pre-cleaned using $\mathrm{Ar}^{+}$ion-beam bombardment for 5 minutes to further reduce the impurities on the substrate surfaces [11]. The system parameters of the $\mathrm{SiO}_{x}, \mathrm{TaO}_{x}$ and $\mathrm{TiO}_{x}$ barrier layers prepared by IBAD are shown in Table $1[14,15]$.

The film thicknesses of the $\mathrm{SiO}_{x}, \mathrm{TaO}_{x}, \mathrm{TiO}_{x}$ and $\mathrm{TaO}_{x} / \mathrm{SiO}_{x}$ barrier layers were in the range of $1-5 \mu \mathrm{m}$, which were recalibrated by post-deposition ellipsometry measurements (VASE, J.A. Woollam Co., Inc.).

The thickness ratio of the $\mathrm{TaO}_{x} / \mathrm{SiO}_{x}$ composite barrier layer should be suitable to achieve a good breakdown field strength effect, and the suitable thickness ratio of the $\mathrm{SiO}_{x}$ and the $\mathrm{TaO}_{x}$ is calculated as following [16,17]:

$\frac{d_{1}}{d_{2}}=\frac{E_{2 \mathrm{~B}}}{E_{1 \mathrm{~B}}}-\frac{\varepsilon_{1}}{\varepsilon_{2}}$

where the $E_{1 \mathrm{~B}}$ and $E_{2 \mathrm{~B}}$ are the breakdown field strength of $\mathrm{SiO}_{x}$ and $\mathrm{TaO}_{x}$, and the $\varepsilon_{1}$ and $\varepsilon_{2}$ are the permittivity of $\mathrm{SiO}_{x}$ and $\mathrm{TaO}_{x}$. With $E_{1 \mathrm{~B}}=4.86$ $\mathrm{MV} / \mathrm{cm}, E_{2 \mathrm{~B}}=2.67 \mathrm{MV} / \mathrm{cm}, \varepsilon_{1}=3.5$ and $\varepsilon_{2}=27$, which are obtained from the average values of five measurements of the barrier layers, $\frac{d_{1}}{d_{2}}$ can be calculated to be 0.42 .

Assuming that the thickness of $\mathrm{TaO}_{x} / \mathrm{SiO}_{x}$ composite barrier layer is $1 \mu \mathrm{m}$, we have estimated that the thicknesses of $\mathrm{SiO}_{x}$ layer is $296 \mathrm{~nm}$ and $\mathrm{TaO}_{x}$ layer $704 \mathrm{~nm}$. Since the adhesion between the $\mathrm{TaO}_{x}$ layer and the steel foil is better than that between the $\mathrm{SiO}_{x}$ layer and the steel foil, the $\mathrm{TaO}_{x}(704 \mathrm{~nm})$ layer has been prepared on the steel foil firstly and then the $\mathrm{SiO}_{x}(296 \mathrm{~nm})$ layer has been deposited. Different thicknesses of $\mathrm{TaO}_{x} / \mathrm{SiO}_{x}$ composite barrier layers can be obtained by repeating this process for several cycles.

The surface morphologies of the prepared barrier layers were analyzed using atomic force microscopy (AFM, Needle-Sensor, TwinSNOM, from Omicron Nano-Technology $\mathrm{GmBH}$ ), operated in the contact mode in conditions resulting in 50-nm lateral resolution.

The measuring program of the dielectric properties of the barrier layers is as follows: $90 \mathrm{Cu}$ contacts with a diameter of $1 \mathrm{~mm}$ were deposited through a Ti mask onto the barrier-coated steel foils, and the data were averaged to characterize the dielectric properties of the barrier layers. The experimental program of the resistance of barrier layers to fatigue failure is shown as follows: the stainless-steel foils coated with the barrier layers and $\mathrm{Cu}$ electrodes were subjected to 500 cycles of outward or inward bending around a cylinder with variable radius ( $R=15 \mathrm{~mm}, 25 \mathrm{~mm}, 35 \mathrm{~mm}$ ). After the bent specimen foils were
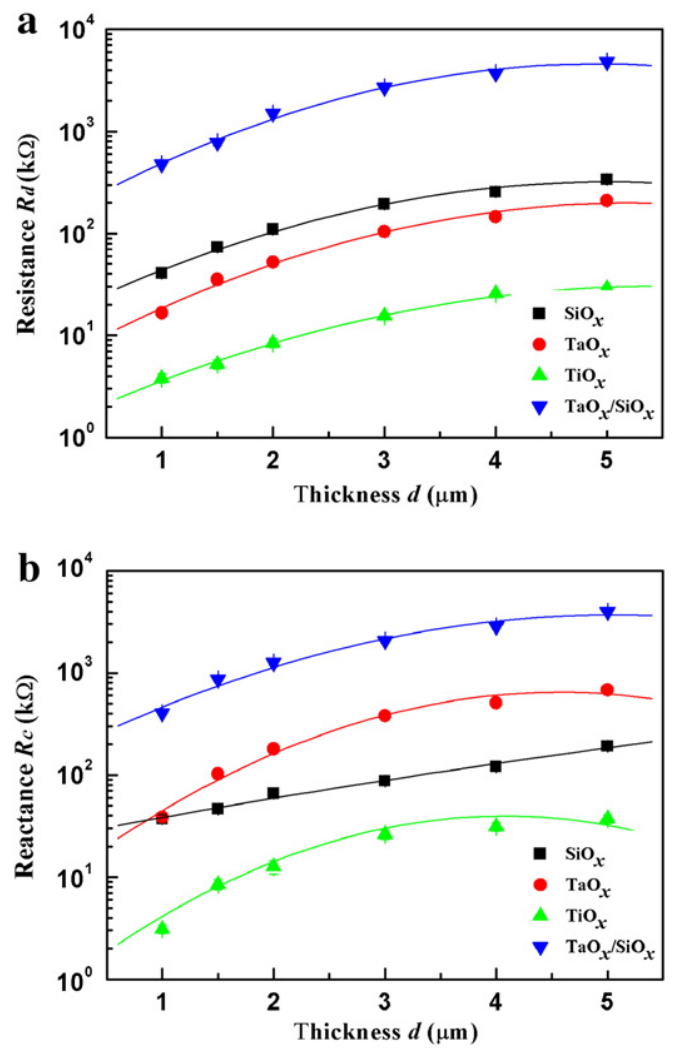

Fig. 1. Relationship between impedance and thickness of barrier layers: (a) Resistance; (b) Reactance. Error bars represent the standard deviation of 5 measured data points.

flattened, the insulation resistance of the barrier layers was measured by applying a direct current voltage of $30 \mathrm{~V}$ between the $\mathrm{Cu}$ electrode and the stainless-steel foil. The resistance of barrier layers to fatigue failure was evaluated by an insulation ratio, which was equal to N/90, $\mathrm{N}$ being the number of the $\mathrm{Cu}$ electrodes where the insulation resistance was $10^{8} \Omega \cdot \mathrm{cm}^{2}$ or higher. Detailed measuring program of the dielectric properties and the resistance to fatigue failure of barrier layers was described in reference [11].

\section{Results and discussion}

\subsection{Dielectric properties}

\subsubsection{Impedance}

Under the alternating current measuring mode, the barrier layer impedance consists of resistance and reactance $\left(Z=R_{\mathrm{d}}+i R_{\mathrm{c}}\right)$. The resistance and reactance of the $\mathrm{SiO}_{x}, \mathrm{TaO}_{x}, \mathrm{TiO}_{x}$ and $\mathrm{TaO}_{x} / \mathrm{SiO}_{x}$ barrier layers deposited by IBAD are shown in Fig. 1(a) and (b), respectively. From Fig. 1(a) and (b), we can see that the resistance and reactance of the $\mathrm{SiO}_{x}, \mathrm{TaO}_{x}, \mathrm{TiO}_{x}$ and $\mathrm{TaO}_{x} / \mathrm{SiO}_{x}$ barrier layers does not increase lineally with the thickness increasing, and the resistance and reactance of the $\mathrm{TaO}_{x} / \mathrm{SiO}_{x}$ composite barrier layers is greatly higher than that of the $\mathrm{SiO}_{x}$ or the $\mathrm{TaO}_{x}$ barrier layers. Meantime, the resistance and reactance of the $\mathrm{SiO}_{x}$ or the $\mathrm{TaO}_{x}$ barrier layers is higher by 2 orders of magnitude than that of the $\mathrm{TiO}_{x}$ barrier layers with the same thickness. This can be explained by: (1) under the preparation parameters in Table 1, the $\mathrm{TiO}_{x}$

Table 1

Preparation parameters of $\mathrm{SiO}_{x}, \mathrm{TaO}_{x}$ and $\mathrm{TiO}_{x}$ barrier layers.

\begin{tabular}{|c|c|c|c|c|c|c|c|}
\hline Films & Accelerating voltage/V & beam current $/ \mathrm{mA}$ & $\mathrm{O}_{2} / \mathrm{sccm}$ & $\mathrm{Ar} / \mathrm{sccm}$ & Evaporation rate $/\left(\mathrm{nm} \cdot \mathrm{s}^{-1}\right)$ & Vacuum $/ 10^{-2} \mathrm{~Pa}$ & Temperature $/{ }^{\circ} \mathrm{C}$ \\
\hline $\mathrm{SiO}_{x}$ & 330 & 100 & 0 & 6 & 0.60 & 0.9 & $30-70$ \\
\hline $\mathrm{TaO}_{x}$ & 330 & 100 & 23 & 3 & 0.30 & 2.0 & $30-70$ \\
\hline $\mathrm{TiO}_{x}$ & 330 & 100 & 23 & 3 & 0.30 & 2.0 & $30-70$ \\
\hline
\end{tabular}



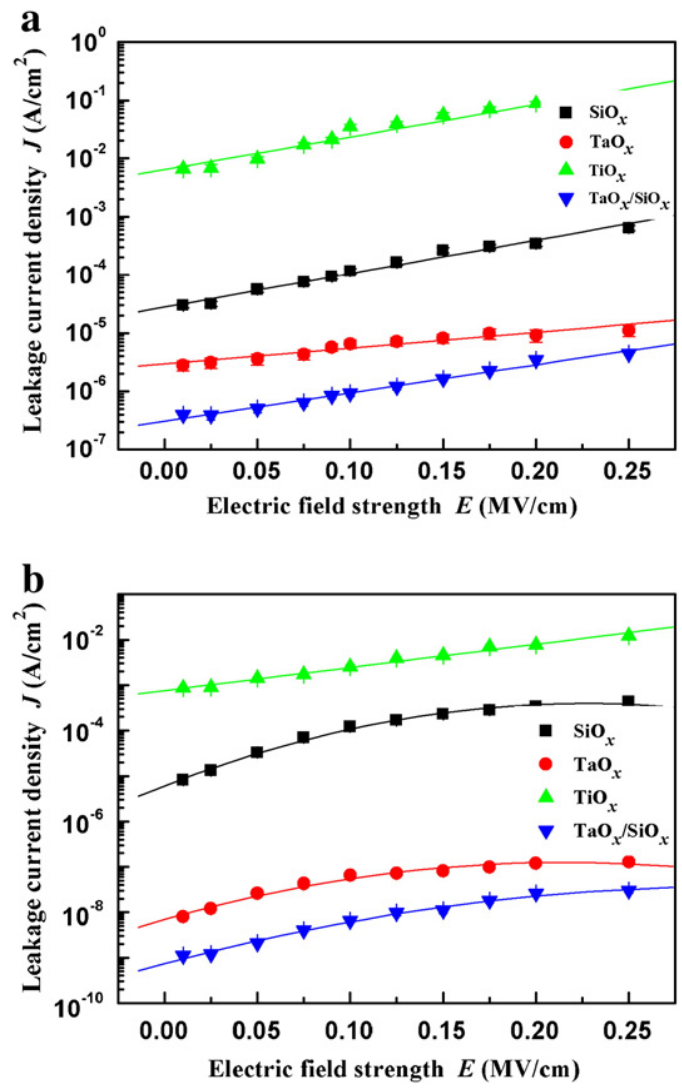

Fig. 2. Relationship between leakage current density $J$ and electric field strength $E$ of barrier layers at different thicknesses: (a) $3 \mu \mathrm{m}$; (b) $4 \mu \mathrm{m}$. Error bars represent the standard deviation of 5 measured data points. barrier layer usually forms a polycrystalline structure (e.g. Anatase, Rutile, Brookite, the titanium ions are not completely oxidized), and the $\mathrm{SiO}_{x}$ or the $\mathrm{TaO}_{x}$ barrier layer usually forms an amorphous structure. Therefore, more metal ions present in the $\mathrm{TiO}_{x}$ barrier layer compared to the $\mathrm{SiO}_{x}$ or the $\mathrm{TaO}_{x}$ barrier layer, so the impedance of the $\mathrm{TiO}_{x}$ barrier layer is lower than that of the $\mathrm{SiO}_{x}$ or the $\mathrm{TaO}_{x}$ barrier layer [18]; (2) the intrinsic structure of the $\mathrm{SiO}_{x}$ or the $\mathrm{TaO}_{x}$ barrier layer is denser than that of the $\mathrm{TiO}_{x}$ barrier layer, for the tensile stress value of the $\mathrm{SiO}_{x}$ or the $\mathrm{TaO}_{x}$ barrier layer is about $40 \mathrm{M}$ Pa lower than that of the $\mathrm{TiO}_{x}$ barrier layer $[19,20]$; (3) the $\mathrm{TaO}_{x} / \mathrm{SiO}_{x}$ composite barrier layer forms a staggered structure, which could remedy the deficiencies of each layer, so less $\mathrm{Cu}$ atoms of electrode can permeate into the $\mathrm{TaO}_{x} / \mathrm{SiO}_{x}$ composite barrier layer during $\mathrm{Cu}$ film coating for its dense structure. In short, the above physical phenomenon might be explained by the intrinsic material properties and the structures of the barrier layers.

\subsubsection{Leakage current density}

The relationship between leakage current density $(J)$ and electric field strength $(E)$ of the $\mathrm{SiO}_{x}, \mathrm{TaO}_{x}, \mathrm{TiO}_{x}$ and $\mathrm{TaO}_{x} / \mathrm{SiO}_{x}$ barrier layers is shown in Fig. 2(a) and (b), of which the barrier layer thicknesses are $3 \mu \mathrm{m}$ and $4 \mu \mathrm{m}$. Under the same electric field strength, the leakage current density of the $\mathrm{SiO}_{x}$ or the $\mathrm{TaO}_{x}$ barrier layer is lower by $2-4$ orders of magnitude than that of the $\mathrm{TiO}_{x}$ barrier layer, and the leakage current density of the $\mathrm{TaO}_{x} / \mathrm{SiO}_{x}$ composite barrier layer is lower than that of the $\mathrm{SiO}_{x}$ or the $\mathrm{TaO}_{x}$ barrier layer. The reasons are as follows: (1) as the previous analysis, the impedance of the $\mathrm{TaO}_{x} / \mathrm{SiO}_{x}$ composite barrier layer is much higher than that of the $\mathrm{SiO}_{x}$ or the $\mathrm{TaO}_{x}$ barrier layer, and the impedance of the $\mathrm{SiO}_{x}$ or the $\mathrm{TaO}_{x}$ barrier layer is higher than that of the $\mathrm{TiO}_{x}$ barrier layer. The leakage current density of the barrier layers decreases with the impedance increasing under the same electric field strength; (2) the $\mathrm{SiO}_{x}$ or the $\mathrm{TaO}_{x}$ barrier layer is denser and smoother than the $\mathrm{TiO}_{x}$ barrier layer, and the $\mathrm{TaO}_{x} / \mathrm{SiO}_{x}$ composite barrier layer is denser than the $\mathrm{SiO}_{x}$ or the $\mathrm{TaO}_{x}$ barrier layer from the peak-valley values (Z-axis scales) of the AFM images shown in Fig. 3. It also can be found that there are fewer pin-holes, impurities and defects in the
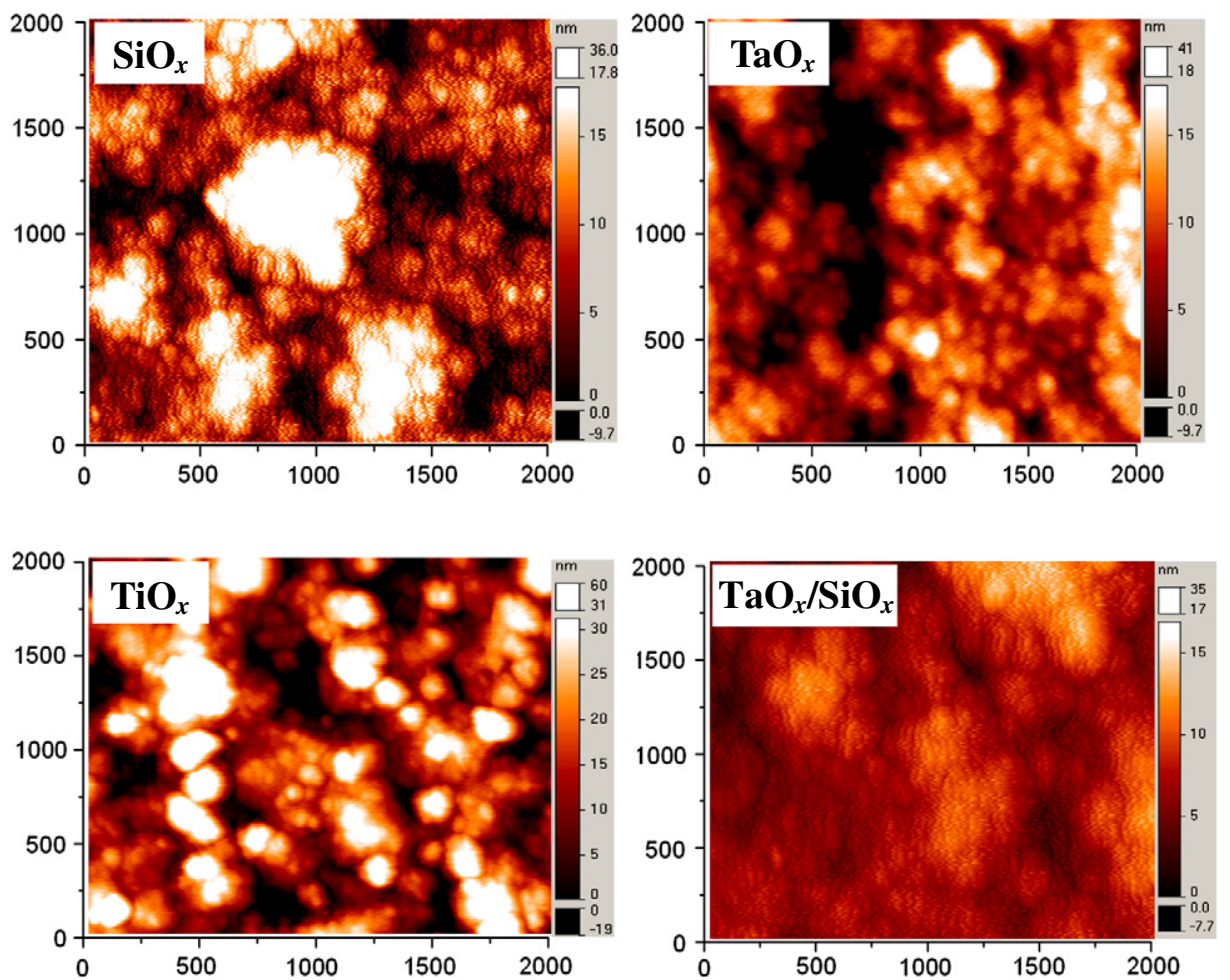

Fig. 3. AFM images of $\mathrm{SiO}_{x}, \mathrm{TaO}_{x}, \mathrm{TiO}_{x}$ and $\mathrm{TaO}_{x} / \mathrm{SiO}_{x}$ barrier layers. 
$\mathrm{TaO}_{x} / \mathrm{SiO}_{x}$ composite barrier layer for its staggered structure. Therefore, the structure of the $\mathrm{TaO}_{x} / \mathrm{SiO}_{x}$ composite barrier layer leads to the lowest leakage current density.

As shown in Fig. 2, the leakage current density responds linearly to the electric field strength when the thickness is $3 \mu \mathrm{m}$, but the relationship changes when the thickness is $4 \mu \mathrm{m}$ (except for $\mathrm{TiO}_{x}$ ). The reason is that the effect of the electric field strength on the leakage current density of the latter is less sensitive than that of the former for the denser $\mathrm{SiO}_{x}, \mathrm{TaO}_{x}$ and $\mathrm{TaO}_{x} / \mathrm{SiO}_{x}$ barrier layers.

\subsubsection{Breakdown field strength and performance index}

The breakdown voltage $(U)$ of barrier layers is defined as the voltage at which the current increases sharply. All the thicknesses of the barrier layers are kept the same as $d=500 \mathrm{~nm}$. The breakdown field strength $\left(E_{\mathrm{BD}}\right)$ is calculated according to the following formula: $E_{\mathrm{BD}}=\frac{U}{d}$, and the data are analyzed by averaging. The results are shown in Table 2 .

The critical charge density or electric displacement when the barrier layers are broken down is called the performance index $\left(Q_{\mathrm{BD}}\right)$, which is equal to the product of the permittivity $(\varepsilon)$ and the breakdown field strength $\left(E_{\mathrm{BD}}\right): \mathrm{Q}_{\mathrm{BD}}=\varepsilon \times E_{\mathrm{BD}}\left(\varepsilon=\varepsilon_{r} \varepsilon_{0}\right)$. The performance indexes of all barrier layers are also shown in Table 2 .

From the above data we can know that the $E_{\mathrm{BD}}$ of the $\mathrm{SiO}_{x}$ barrier layer is the highest among the single barrier layers, and the $\mathrm{Q}_{\mathrm{BD}}$ of the $\mathrm{TaO}_{x}$ barrier layer is the best. However, the $E_{\mathrm{BD}}$ and $\mathrm{Q}_{\mathrm{BD}}$ of the $\mathrm{TaO}_{x} / \mathrm{SiO}_{x}$ composite barrier layer are higher than those of the $\mathrm{SiO}_{x}$ or the $\mathrm{TaO}_{x}$ barrier layer. This is because the composite barrier layer can change the way of breakdown from spread type into self-healing type, which can increase the breakdown field strength and the surface charge density of the barrier layer, and remedy the deficiencies of the single barrier layer [17]. Meantime, there are fewer pin-holes, impurities and defects in the $\mathrm{TaO}_{x} / \mathrm{SiO}_{x}$ composite barrier layer. So, most breakdown of the $\mathrm{TaO}_{x} / \mathrm{SiO}_{x}$ composite barrier layer is intrinsic, but it is non-intrinsic for the $\mathrm{TiO}_{x}$ barrier layer because of its defects and loose structure. To summarize, the comprehensive properties of permittivity and breakdown field strength of the $\mathrm{TaO}_{x} / \mathrm{SiO}_{x}$ composite barrier layer is the best, which fully demonstrates that the composite barrier layer can complement the deficiencies and defects of each single barrier layer, and make the dielectric parameters better than those of single barrier layer.

\subsection{Resistance to fatigue failure}

Because the dielectric properties of the $\mathrm{TiO}_{x}$ barrier layer cannot meet the insulation requirements, the resistance to fatigue failure of the $\mathrm{TiO}_{x}$ barrier layer is beyond our consideration. When the $\mathrm{SiO}_{x}$, $\mathrm{TaO}_{x}$ and $\mathrm{TaO}_{x} / \mathrm{SiO}_{x}$ barrier layers are bent inward or outward, the corresponding insulation ratios $(\mathrm{N} / 90)$ under different bending radius $(R)$ are shown in Fig. 4(a) and (b), respectively.

From Fig. 4(a) we can see that the insulation ratio of the $\mathrm{TaO}_{x} / \mathrm{SiO}_{x}$ composite barrier layer is the highest and that of the $\mathrm{SiO}_{x}$ barrier layer is the lowest, when the barrier layers are bent inward. This illustrates that the $\mathrm{TaO}_{x} / \mathrm{SiO}_{x}$ composite barrier layer has good resistance to fatigue failure, while that of the $\mathrm{SiO}_{x}$ barrier layer is relatively weak. It is because the periodic alternating layers can effectively balance the residual stress in the whole structure [21]. As the bending radius increases, the insulation ratios of all barrier layers increase gradually, and are up to $100 \%$ at $R \geq 35 \mathrm{~mm}$. The results from Fig. 4(b), when the films are

Table 2

Breakdown field strength and performance index of 500-nm thick barrier layers.

\begin{tabular}{lllll}
\hline Barrier layers & $\mathrm{SiO}_{x}$ & $\mathrm{TaO}_{x}$ & $\mathrm{TiO}_{x}$ & $\mathrm{TaO}_{x} / \mathrm{SiO}_{x}$ \\
\hline $\begin{array}{c}\text { Breakdown field } \\
\text { strength }\end{array}$ & $4.86 \mathrm{MV} / \mathrm{cm}$ & $2.67 \mathrm{MV} / \mathrm{cm}$ & $0.31 \mathrm{MV} / \mathrm{cm}$ & $5.29 \mathrm{MV} / \mathrm{cm}$ \\
$\begin{array}{c}\text { Performance } \\
\text { index }\end{array}$ & $1.70 \mu \mathrm{c} / \mathrm{cm}^{2}$ & $6.68 \mu \mathrm{c} / \mathrm{cm}^{2}$ & $0.86 \mu \mathrm{c} / \mathrm{cm}^{2}$ & $14.59 \mu \mathrm{c} / \mathrm{cm}^{2}$ \\
\hline
\end{tabular}
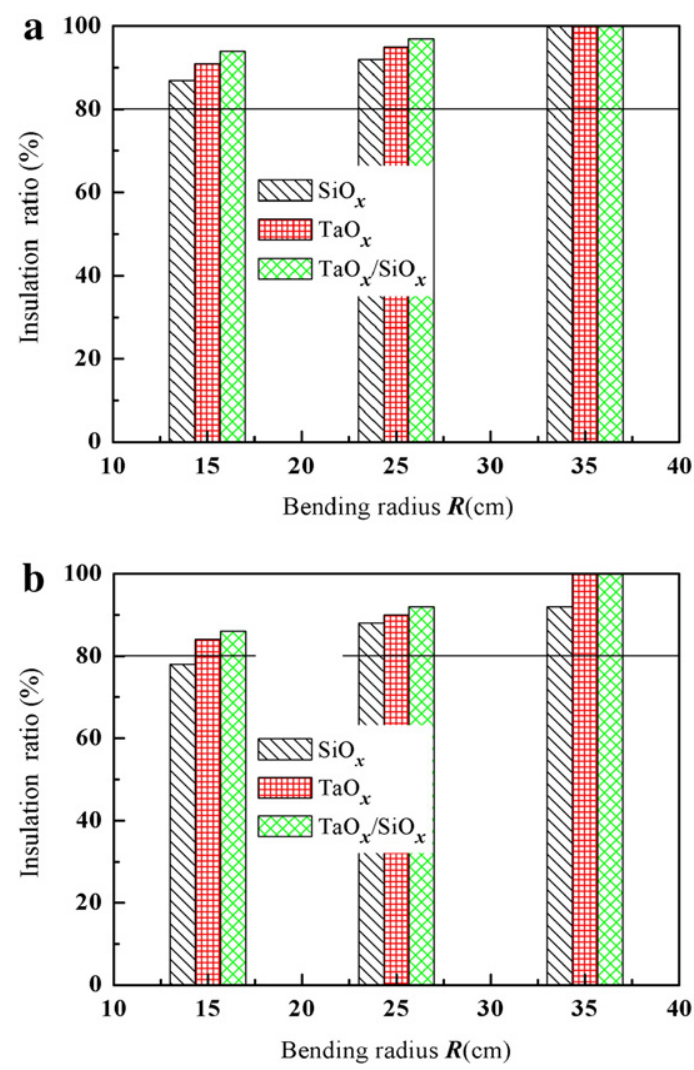

Fig. 4. Relationship between bending radius and insulation ratio of barrier layers: (a) Inward bending; (b) Outward bending.

bent outward, are similar with those from Fig. 4(a), except that the insulation ratios are lower than those of inward bending. The differences indicate that the resistance to fatigue failure of barrier layers in inward bending is better than those in outward bending under the same bending radius. The reasons are as follows: (1) all barrier layers prepared by IBAD show a tensile stress, and the barrier layers have a shrink trend compared to the steel foils [22-24]; (2) the tensile stress during outward bending is easier to damage the barriers than that during inward bending, which results in the formation of cracks.

\section{Conclusion}

We have prepared $\mathrm{SiO}_{x}, \mathrm{TaO}_{x}, \mathrm{TiO}_{x}$ and $\mathrm{TaO}_{x} / \mathrm{SiO}_{x}$ as barrier layers on the flexible stainless-steel foils by IBAD, and the dielectric properties and resistance to fatigue failure of all the barrier layers have been investigated. It is indicated that the dielectric properties and resistance to fatigue failure of the $\mathrm{TaO}_{x} / \mathrm{SiO}_{x}$ composite barrier layer are better than those of the $\mathrm{SiO}_{x}$ or the $\mathrm{TaO}_{x}$ barrier layer. Stainless-steel foils coated with the $\mathrm{TaO}_{x} / \mathrm{SiO}_{x}$ composite barrier layers have demonstrated excellent dielectric properties and resistance to fatigue failure. High barrier resistance $\left(R_{\mathrm{d}}>3 \times 10^{8} \Omega \cdot \mathrm{cm}^{2}\right)$, high breakdown field strength $\left(E_{B D}>5 \mathrm{MV} / \mathrm{cm}\right)$ and low leakage current density $\left(J<10^{-8} \mathrm{~A} \cdot \mathrm{cm}^{-2}\right)$ could be achieved by preparing 4- $\mu \mathrm{m}$ thick $\mathrm{TaO}_{x} / \mathrm{SiO}_{x}$ composite barrier layers on stainless-steel foils. The resistance to fatigue failure of all barrier layers in inward bending is better than that in outward bending with the same bending radius. Measurement results of the relationship between leakage current density and the electric field strength have demonstrated the effectiveness of the $\mathrm{TaO}_{x} / \mathrm{SiO}_{x}$ composite barrier layers and their potential for further progress.

\section{References}

[1] M. Wu, S. Wagner, Mater. Res. Soc. Symp. Proc. 609 (2000) A28.5. 
[2] J. Chen, M. Stifanos, W. Fan, J. Nedbal, J. Rose, In: Proceedings of the 2006 International Symposium of the Society for Information Display, San Francisco, U.S.A, June 4-9, 2006, p. 1878.

[3] S.-H. Paek, K.L. Kim, H.-S. Seo, Y.-S. Jeong, S.-Y. Yi, In: Proceedings of the 2006 International Symposium of the Society for Information Display, San Francisco, U.S.A, June 4-9, 2006, p. 1834.

[4] A.N. Tiwari, M. Krejci, E.J. Haug, H. Zogg, Prog. Photovoltaics Res. Appl. 7 (1999) 393.

[5] M. Contreras, B. Egas, K. Ramanathan, J. Hiltner, E. Hasoon, R. Noufi, Prog. Photovoltaics 7 (1999) 311

[6] C.Y. Shi, Y. Sun, O. He, F.Y. Li, J.C. Zhao, Sol. Energy Mater. Sol. Cells 93 (2009) 654

[7] P. Evans, T. English, D. Hammond, M.E. Pemble, D.W. Sheel, Appl. Catal., A 321 (2007) 140.

[8] C. Jin, M. Delmas, P. Aubert, F. Alvarez, T. Minéa, M.C. Hugon, B. Bouchet-Fabre, Thin Solid Films 519 (2011) 4097.

[9] K. Herz, F. Kessler, R. Wachter, M. Powalla, J. Schneider, A. Schulz, Thin Solid Films 403 (404) (2002) 384.

[10] F. Kessler, D. Herrmann, M. Powalla, Thin Solid Films 480 (481) (2005) 491

[11] Y.Q. Li, Z.N. Yu, J. Leng, D.P. Zhang, S. Chen, G. Jin, Thin Solid Films 519 (2011) 4234.
[12] Y.Q. Li, Z.N. Yu, W. Xue, J. Leng, In: International Symposium on Photoelectronic Detection and Imaging 2007: Laser, Ultraviolet, and Terahertz Technology, Beijing, China, September 9-12, 2007, p. 662222-1.

[13] Y.Q. Li, Z.N. Yu, W. Xue, J. Leng, In: Asia Optical Fiber Communication \& Optoelectronic Exposition \& Conference, Shanghai, China, October 17-19, 2007, p. 145.

[14] Z.N. Yu, Y.Q. Li, F. Xia, Z.W. Zhao, W. Xue, Thin Solid Films 517 (2009) 5395

[15] Z.N. Yu, Y.Q. Li, F. Xia, W. Xue, Surf Coat.Technol. 204 (2009) 131.

[16] Y.Q. Li, Ph.D. Thesis, Department of Optical Engineering, Beijing Institute of Technology, P.R.China, 2010 (in Chinese).

[17] C.T. Hsu, Y.J. Lin, Y.K. Su, Y. Meiso, J. Appl. Phys. 72 (1993) 4655.

[18] F. Bin, T. Qi, Opt. Instrum. 26 (2004) 64 (in Chinese).

[19] H.Q. Wang, Ph.D. Thesis, Department of Optical Engineering, Beijing Institute of Technology, P.R.China, 2008 (in Chinese).

[20] Y.Q. Li, Z.N. Yu, H.Q. Wang, W.Q. Lu, W. Xue, Z. Ding, Acta Opt. Sin. 30 (2010) 2 (in Chinese).

[21] P.F. Gu, Z.R. Zhang, Y.J. Zhao, X. Liu, Chin. Phys. Soc. 55 (2006) 6459 (in Chinese).

[22] S.Y. Shao, G.L. Tian, Z.X. Fan, J.D. Shao, Acta Opt. Sin. 25 (2005) 126 (in Chinese)

[23] P.F. Gu, Z.R. Zheng, Y.J. Zhao, X. Liu, Acta Phys. Sin. 55 (2006) 6459 (in Chinese)

[24] J. Leng, Z.N. Yu, Y.Q. Li, D.P. Zhang, X.Y. Liao, W. Xue, Appl. Surf. Sci. 256 (2010) 5832. 